\title{
CORRESPONDENCE
}

Letters of 600 words or less, with minimal allowance for tables, figüires, and rejerences, will be considered for pubiication. Rules regu.rding prior publication, conflict of interest, etc., are the same as for full manuscripts. All letters are subject to editing and condensation. Proofs will not be distributed.

\section{Abnormal Phosphoinositide Turnover in Schizophrenia}

To the Editor:

We read with isterest the recent article by Kaiya et al (26: 669-676; 1989), documenting abnormal phosphoinositide (PI) turnover in schizophrenia. The authors noted increased PI turnover and accumulation of diacylglycerol (DG) in platelets of a subgroup of acute senizophrenic patients, and observed that patients with abnorma PI turnover had a significantly better outcome than other acute schizophrenic $\mathrm{pi}$ tients. The authors further observed that this abnormality was unrelated to neuroleptic treatment or stress, and appeared to be related to the pathophysiology of ihe psychotic state.

According to the authors, DG is a secondary messenger but they did not elaborate on possible neurotransmitters that this finding may implicate in the pathophysiology of schizophrenia. Several neurotransmitters act via the PI system by increasing phospholipase C (Baraban et al 1989), thereby generating DG and inositoi triphosphate. If there is a parallelism between the platelet and brain with regard to the increased phosphoinositide turnover and DG production in schizophrenic patients, this finding would suggest that the activity of any one of these various neurotransmitters (that act by increasing phospholipase C) may be increased in schizophrenia. Acetylcholine (M-1 muscarinic) and serotonin are two candidates, as both act via the phospholipase secondary messenger system (Baraban et al 1989). Increased 5HT-2 activity has been implicated in the pathophysiology of schizophrenia (Mieibach 1989).

Recently, increased muscarinic (M-1) activity has been reported in the psychotic phase of schizophrenic illness (Berger et al 1989; Tandon and Greden 1989). It is suggested that dopamine (DA)/acetylcholine (ACh) balance is important in schizophrenia and that ACh activity increases as a homeostatic response in an effort to maintain this balance in the face of increasing DA activity that occurs in the psychotic phase (Tandon and Greden 1989). This increased muscarinic M-
1 activity may be reflected in increased PI turnover and DG accumulation, as the $M-1$ receptors use the PI system as a secondary messenger. Furthermore, the increase in muscarinic activity would be associated with a better outcome as it would reflect a homeostatic response. If DG accumulation is indicative of increased muscarinic activity, it would be associated with a better outcome, as observed by the authors in this study.

This interpretation is admittedly speculative and alternative explanations are possible; however, it is consistent with current knowledge and provides an explanation for the occurrence of DG accumulation and abnormai FI iurnover, and the association of this finding with good outcome in schizophrenia.

\section{Rajiv Tandon and John F. Greden}

Department of Psychiatry

University of Michigan

Ann Arbor, MI 48109-0120

\section{References}

Baraban JM, Worley PF, Snyder SH (1989): Second messenger systems and $p$ sychoactive drug actions: Focus on the phosphoinositide system and lithium. Am J Psychiatry 146:1251-1260.

Meibach RC (1989): The role of 5-HT2 antagonism in the

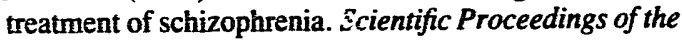
American College of Neuropsychopharmacology Annual Meeting, Maui, p 12.

Tandon R, Greden JF (1989): Cholinergic hyperactivity and negative schizophrenic symptoms: A model of dopaminergic/cholinergic interactions in sctizophrenia. Arch Gen Psychiatry 46:745-753.

\section{Response}

To the Editor:

Drs. Tandon and Greden's interpretation of the findings of our article entitled "Accumulation of Diacylglycerol in Platelet Phosphoinositide Tumover in 